\title{
Validation of Spectral and Broadband UV-B (290 - 325 nm) Irradiance for Canada
}

\author{
Jacqueline Binyamin ${ }^{1}$, John Davies ${ }^{2}$, Bruce McArthur ${ }^{3}$ \\ ${ }^{1}$ University of Winnipeg, Department of Geography, Winnipeg, Canada \\ ${ }^{2}$ McMaster University, School of Geography and Earth Sciences, Hamilton, Canada \\ ${ }^{3}$ Meteorological Service of Canada, Air Quality Research Branch, Toronto, Canada \\ E-mail: j.binyamin@uwinnipeg.ca \\ Received March 20, 2011; revised April 27, 2011; accepted May 10, 2011
}

\begin{abstract}
Stratospheric ozone depletion, as a result of increasing chlorofluorocarbons in the stratosphere, allows more UV-B irradiance $(290-325 \mathrm{~nm})$ to reach the earth's surface with possible detrimental biological effects. Because there are few UV-B radiation stations, irradiance models are useful tools for estimating irradiances where measurements are not made. Estimates of spectral and broadband irradiances from a numerical model are compared with Brewer spectrophotometer measurements at nine Canadian stations (Alert, Resolute Bay, Churchill, Edmonton, Regina, Winnipeg, Montreal, Halifax and Toronto) and 26 years of data. The model uses either the discrete ordinate radiative transfer (DISORT) or the delta-Eddington algorithms to solve the radiative transfer equation for a 49-layer, vertically inhomogeneous, plane-parallel atmosphere, with cloud inserted between the 2 and $3 \mathrm{~km}$ heights. Spectral calculations are made at $1 \mathrm{~nm}$ intervals. The model uses extraterrestrial spectral irradiance, spectral optical properties for each atmospheric layer for ozone, air molecules, and aerosol and surface albedo. A fixed broadband cloud optical depth of 27 was satisfactory for calculating cloudy sky irradiances at all stations except in the arctic.

Comparisons are made both for daily totals and for monthly averaged spectral and broadband irradiances. The delta-Eddington method is shown to be unsuitable for calculating spectral irradiances under clear skies, at wavelengths less than $305 \mathrm{~nm}$ where absorption by ozone is high, and at large solar zenith angles. The errors are smaller for overcast conditions. The method is adequate for daily total and monthly averaged spectral $(\geq 305 \mathrm{~nm})$ and broadband calculations for all sky conditions, although consistently overestimating irradiances. There is a good agreement between broadband measurements and calculations for both daily totals and monthly averages with mean bias error mainly less than $5 \%$ of the mean measured daily irradiance and root mean square error less than $25 \%$, decreasing to below $15 \%$ for monthly averages.
\end{abstract}

Keywords: Modelling UV-B Radiation, DISORT, Delta-Eddington, Spectral and Broadband Radiation, Brewer Spectrophotometer, UV-B Measurements in Canada

\section{Introduction}

Human made chemicals, including chlorofluorocarbons and other halocarbons, have damaged the stratospheric ozone layer that protects people, plants, and animals from harmful biologically active ultraviolet (UV-B) irradiance. The effective UV-B waveband is from 290 to $325 \mathrm{~nm}$, which is the wavelength range of the Canadian Brewer spectrophotometer measurements. Even though the UV$\mathrm{B}$ band is biologically important, it contains little energy, constituting only $1.8 \%$ of the total solar radiation at the top of the atmosphere, and no more than $1 \%$ at the earth's surface [1].

Within the UV-B band the atmosphere becomes more transparent with increasing wavelength since ozone absorption decreases by two orders of magnitude as wavelength increases between $290-325 \mathrm{~nm}$ [2]. Over this wavelength range the irradiance at the ground may vary through eleven orders of magnitude. Biological effects are not constant across the waveband. In general, the shorter the wavelength is, the greater the biological effect [3]. Therefore, spectral measurements are essential for 
biological applications.

UV-B irradiance measurements are rare in Canada and the world. Radiative transfer models are potentially very important tools to supplement the spatially sparse network. The DISORT and delta-Eddington algorithms have been used widely to model irradiance [4-7]. Delta-Eddington uses a two-term expansion of the scattering phase function but DISORT allows for any number of expansions of the phase function, therefore, it is potentially an exact solution. Comparisons between both methods for model atmospheres for UV transmittance (290 - 400 $\mathrm{nm}$ ) for various amounts of absorption and scattering have been made by Forster and Shine [8]. Here, we present the first extensive comparison of the two methods for real atmospheres in the UV-B waveband.

Forster and Shine [8] showed that the delta-Eddington is not suitable for calculating spectral values for clear skies and at large solar zenith angles but for overcast skies it may be suitable. For thick scattering cloud layers, the two-term expansion is sufficient because multiple scattering is dominant and not too sensitive to detailed phase function structure $[9,10]$. Erlick and Frederick [11] compared the delta-Eddington flux calculations with the 22-stream DISORT model for an isolated optically-thick cloud layer $(\tau=40)$ at $290 \mathrm{~nm}$ with zero surface albedo. They found that transmission and reflection from these two methods were closely matched except for large zenith angles greater than $60^{\circ}$ where the delta-Eddington transmissivity and reflectivity were too high and too low (by 10\%) respectively. Lubin et al. [12] argued that the uncertainties in spectral irradiance calculations using the delta-Eddington approximation instead of DISORT are less than the uncertainties involved in treating clouds as plane parallel layers.

Validation studies that have compared model calculations with measurements are mostly restricted to data for just a few days and cloudless skies [13-15]. Few studies have validated surface-based models for all sky conditions $[6,16,17]$. This is the first comprehensive study for Canada. A pilot study was performed by Davies et al. [7] at four Canadian stations (Bedford, Toronto, Winnipeg, Edmonton) using a small amount of data.

Comparison between UV-B irradiance calculated by DISORT model and measurements have been presented by Wang and Lenoble [5], Zeng et al. [14] and Pachart et al. [18] for clear sky conditions. Wang and Lenoble [5] concluded that the variation of the ratio between measurement and model spectral results exceeds $\pm 20 \%$, but the agreement is better than $\pm 6 \%$ when the ratio is averaged over intervals of $10 \mathrm{~nm}$. Zeng et al. [14] compared measured spectral irradiances with 8-stream DISORT results. They found that UV-B irradiances could be predicted to within $8 \%$ if the input parameters were well known. These differences are due to calibration errors either in the instrument or in the extraterrestrial spectral irradiance.

Our study is important because scientists in Canadahave found that an average ozone depletion of about $6 \%$ has been observed over five Canadian monitoring stations (Toronto, Goose Bay, Edmonton, Churchill and Resolute Bay) since the late 1970s [19]. In Toronto $\left(43^{\circ} 47^{\prime} \mathrm{N}, 79^{\circ} 28^{\prime} \mathrm{W}\right)$ Kerr and McElroy [20] reported decreases in the ozone levels between 1989 and 1993 of $4.1 \%$ and $1.8 \%$ per year in winter and summer, respectively.

This paper evaluates a numerical model for UV-B irradiance for all sky conditions, validates spectral and broadband irradiances using Brewer spectrophotometer measurements, and assesses the relative usefulness of the DISORT and delta-Eddington algorithms in calculating spectral and broadband irradiances.

Section 2 and 3 describe the irradiance and ozone measurements. Section 4 introduces the model and the input parameters. Section 5 presents the model validation results. Section 6 gives conclusions, emphasizes the contributions of this research and details some of the future research needs.

\section{The Brewer Measurements}

Spectral UV-B irradiance measurements in Canada began in March 1989 and are made at 13 locations with the Canadian designed single monochromatic Brewer spectrophotometer. Nine of these locations, which have the necessary meteorological data for radiative transfer calculation, are used in this study (Figure 1). The Brewer instrument allows the calculation of daily ozone depth and measures spectral irradiance for wavelengths between 290 and $325 \mathrm{~nm}$ at a resolution of $0.5 \mathrm{~nm}$. Each spectral measurement consists of the average of a forward and backward scan across the wavelength range, which takes about 8 minutes to complete [20]. Measurements of the radiation intensity that falls on a horizontal diffusing surface are made once or twice each hour throughout the day from sunrise to sunset at irregular times in GMT. These spectral measurements were obtained from the World Ozone and Ultraviolet Radiation Data Centre (WOUDC).

The Brewer instruments have known uncertainties. They receive stray light from longer wavelengths adjacent to the one being measured [21,22] which affects measurements below about $305 \mathrm{~nm}$ where the light intensity is very small. Also, they are subject to cosine error such that measurements usually underestimate the horizontal global irradiance by up to $8 \%$ depending on clouds, aerosols, and solar zenith angle [23,24]. Each 


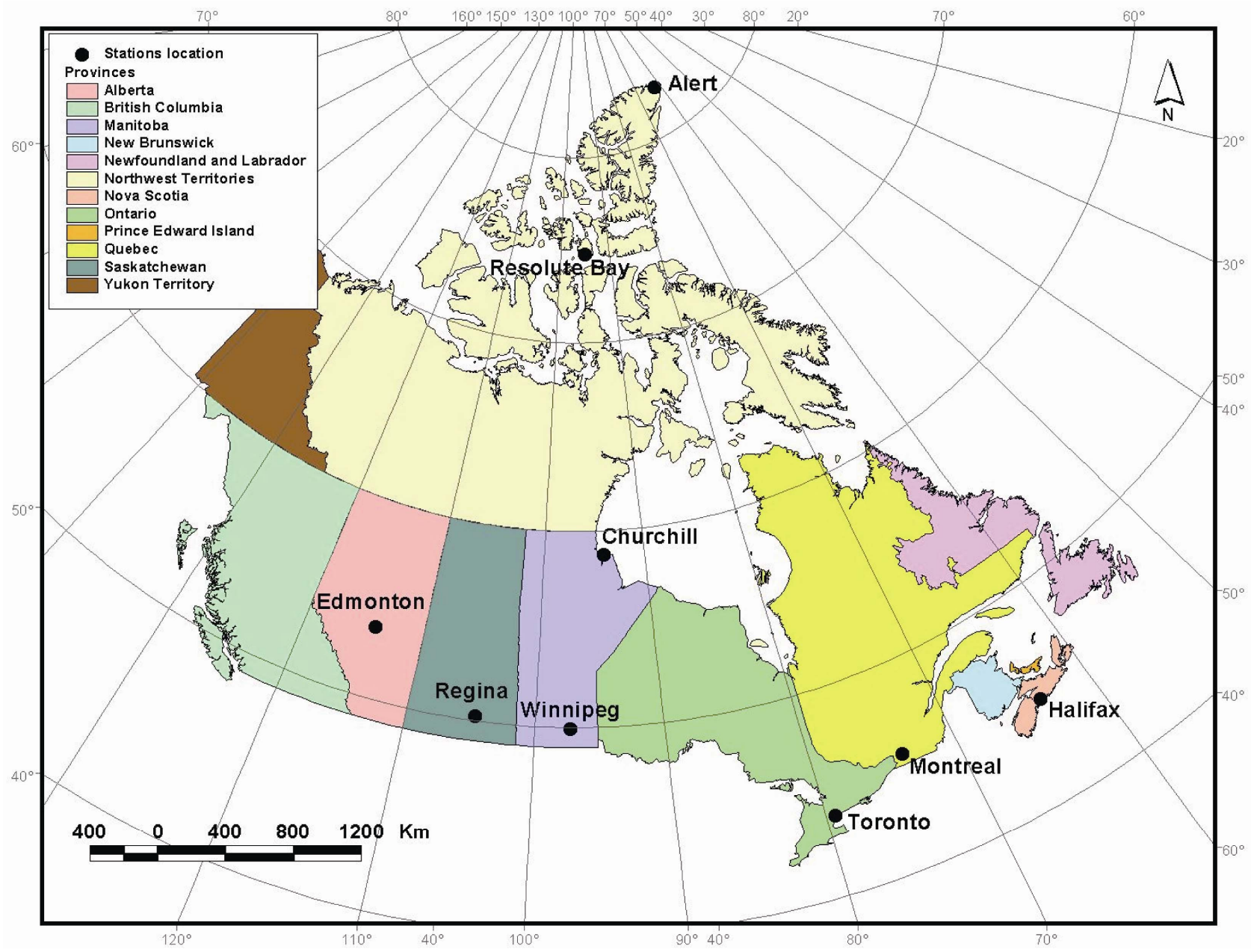

Figure 1. Location of Canadian stations used in the study.

instrument has its own cosine error, which can vary from $2 \%$ to $20 \%$ [e.g., 24,25$]$.

Calibration uncertainty for the Brewer instruments ranges from $\pm 5-7 \%[26,27]$. The Brewer instrument is also affected by ambient temperature and humidity variations [21]. It is provided with a temperature-stabilized enclosure but this does not totally eliminate the temperature variability. The temperature effect is greater at shorter wavelengths and can produce mean errors ranging from $-2 \%$ to $2 \%$ in winter and summer, respectively over the Brewer spectral range [23]. However, Cappellani and Kochler [28] have found that for winter days (temperature range $9.8^{\circ}$ to $21.7^{\circ} \mathrm{C}$ ) and for summer days (temperature range $21.7^{\circ}$ to $42^{\circ} \mathrm{C}$ ), the Brewer values should be increased by $2 \%$ and $8 \%$, respectively.

Some quality control procedures are performed by the Meteorological Service of Canada (MSC). These include: calibration with 1000 -watt standard lamps that are traceable to the US National Institute of Standards and Technology; daily radiometric stability that is maintained with an internal 20-watt quartz halogen lamp; a wavelength check is made several times per day using a mercury discharge lamp; and a correction for stray light [23]. However, corrections for the effect of cosine error on the UV$\mathrm{B}$ spectra and a wavelength-dependent temperature effect are not applied. In this study an increase of $6 \%$ was applied to the Brewer data to compensate for the cosine error effect on the basis of research by Krotkov et al. [29] and Wang et al. [27].

\section{Other Measurements}

Daily total ozone column measurements from the Brewer instrument were obtained from the WOUDC for the stations shown in Figure 1. Hourly (local standard time) measurements of total cloud opacity, surface temperature, pressure and relative humidity were provided by the MSC. Values were linearly interpolated for the irradiance measurement times in GMT. Solar zenith angles for each measurement time and the ratio of actual to mean 
Sun-Earth distance were calculated following Michalsky [30]. Daily snow depth measurements were provided by the MSC.

\section{Davies Model Description}

Surface irradiance $G$ is expressed as a cloudiness- scaled combination of cloudless sky irradiance $G_{o}$ and overcast sky irradiance $G_{\otimes}$ :

$$
G=(1-C) G_{\mathrm{O}}+C G_{\otimes},
$$

where $C$ is the fraction of the sky that is cloud covered. $G_{o}$ and $G_{\otimes}$ are calculated spectrally at $1 \mathrm{~nm}$ intervals using either the DISORT [31] or the delta-Eddington [32] solutions to the radiative transfer equation.

This model can be applied anywhere where there are daily measurements of column ozone and snow depth and hourly cloud cover observations. Radiative transfer calculations of $G_{o}$ and $G_{\otimes}$ require the spectral UV-B irradiance emitted by the sun and the spectral optical properties for each atmospheric layer for ozone absorption, Rayleigh scattering, aerosol extinction, and cloud scattering and surface albedo.

In this study, the atmosphere is divided into 49 layers with constant scattering and absorbing properties within each. The layers are thin $(1 \mathrm{~km})$ in the lower atmosphere, intermediate $(2.5 \mathrm{~km})$ in the middle atmosphere and thick $(5 \mathrm{~km})$ in the upper atmosphere. Each layer is regarded as horizontally homogeneous and the curvature associated with sphericity of the earth is ignored. Layer values of spectral optical depths, single scattering albedos and asymmetry factors were calculated as layer averages. These spectral optical properties were combined for each wavelength and layer. The cloud is placed in one layer (between 2 and $3 \mathrm{~km}$ ) and in this plane-parallel atmosphere radiation transfer is considered only in the vertical. In the calculation, cloud optical properties replace optical properties for the cloudless layer between 2 and $3 \mathrm{~km}$.

The model uses solar spectral extraterrestrial irradiances from the Solar Ultraviolet Spectral Irradiance Monitor (SUSIM) instrument on board the third Atmospheric Laboratory for Applications and Science (ATLAS-3) space shuttle mission launched on Nov. 13, 1994 (D. Prinz, personal communication, 2007), ozone absorption coefficients from Paur and Bass [33], Rayleigh scattering cross sections following Elterman [34], aerosol optical properties from Shettle and Fenn [35]. Since the Brewer instrument measures irradiance through a triangular filter with a base of $1.1 \mathrm{~nm}$ (full width at half maximum of $0.55 \mathrm{~nm}$ ), the high spectral resolution (full width at half maximum $\sim 0.15 \mathrm{~nm}$, sampled approximately every $0.05 \mathrm{~nm})$ SUSIM data were averaged to mimic the Brewer. SUSIM measurements for average Sun - Earth distance were selected from the 289.45 and $326.55 \mathrm{~nm}$ wavelength range at a $0.05 \mathrm{~nm}$ interval, and averaged for each nanometer from 290 to $325 \mathrm{~nm}$.

Since there are few measured atmospheric vertical profiles of ozone, temperature, pressure and humidity, standard model atmospheres containing these vertical profiles for 50 atmospheric levels from the surface to 120 $\mathrm{km}$ in LOWTRAN 7 [36] were used for the model in this study. Summer and winter midlatitude and subarctic model atmospheres were used to calculate Rayleigh and ozone optical depths. Urban aerosol optical properties for $50 \mathrm{~km}$ and $36.5 \mathrm{~km}$ visibilities were used for the boundary layer for both Toronto and Montreal and a $50 \mathrm{~km}$ visibility rural aerosol was used for all other stations. Ozone concentrations were scaled by the ratio of total measured to total model atmospheric ozone depth.

For this study, Broadband values of cloud single scattering albedo $\omega$ and asymmetry factor $g_{c}$ were set at 0.999997 and 0.8709 , respectively, for equivalent radius of $7 \mu \mathrm{m}$ (for arctic stations) and 0.999995 and 0.8587 , respectively, for equivalent radius of $10 \mu \mathrm{m}$ (for midlatitude and subarctic stations) at all wavelengths [37]. Broadband cloud optical depths $\tau_{c}$ were calculated iteratively from overcast irradiance measurements for snow free conditions to eliminate irradiance increase from multiple scattering between cloud and snow [37].

Surface albedo measurements for the UV-B band are not available in Canada. Albedo was calculated following Davies et al. [7] as a linear function of daily snow depth measurement between 0.05 for a snow free ground [38] and 0.75 for a snow cover of $30 \mathrm{~cm}$ or greater. Albedo is independent of wavelength and the effects of melting and snow contamination are ignored.

\section{Validation of Model Irradiances}

The section assesses the model's performance in calculating spectral and broadband irradiances using the extraterrestrial solar spectrum, the calculated spectral optical parameters, and the broadband cloud optical depths given in Binyamin et al. [37]. Although the results in Binyamin et al. [37] showed that the DISORT 8 and delta-Eddington algorithms yielded very similar cloud optical depths for all stations in the study it is also important to examine how well irradiances from the two methods compare since the delta-Eddington method is an approximate solution of the radiative transfer equation whereas the DISORT 8 method is close to an exact solution.

\subsection{Performance Measures}

Model performance is assessed using the mean bias error 

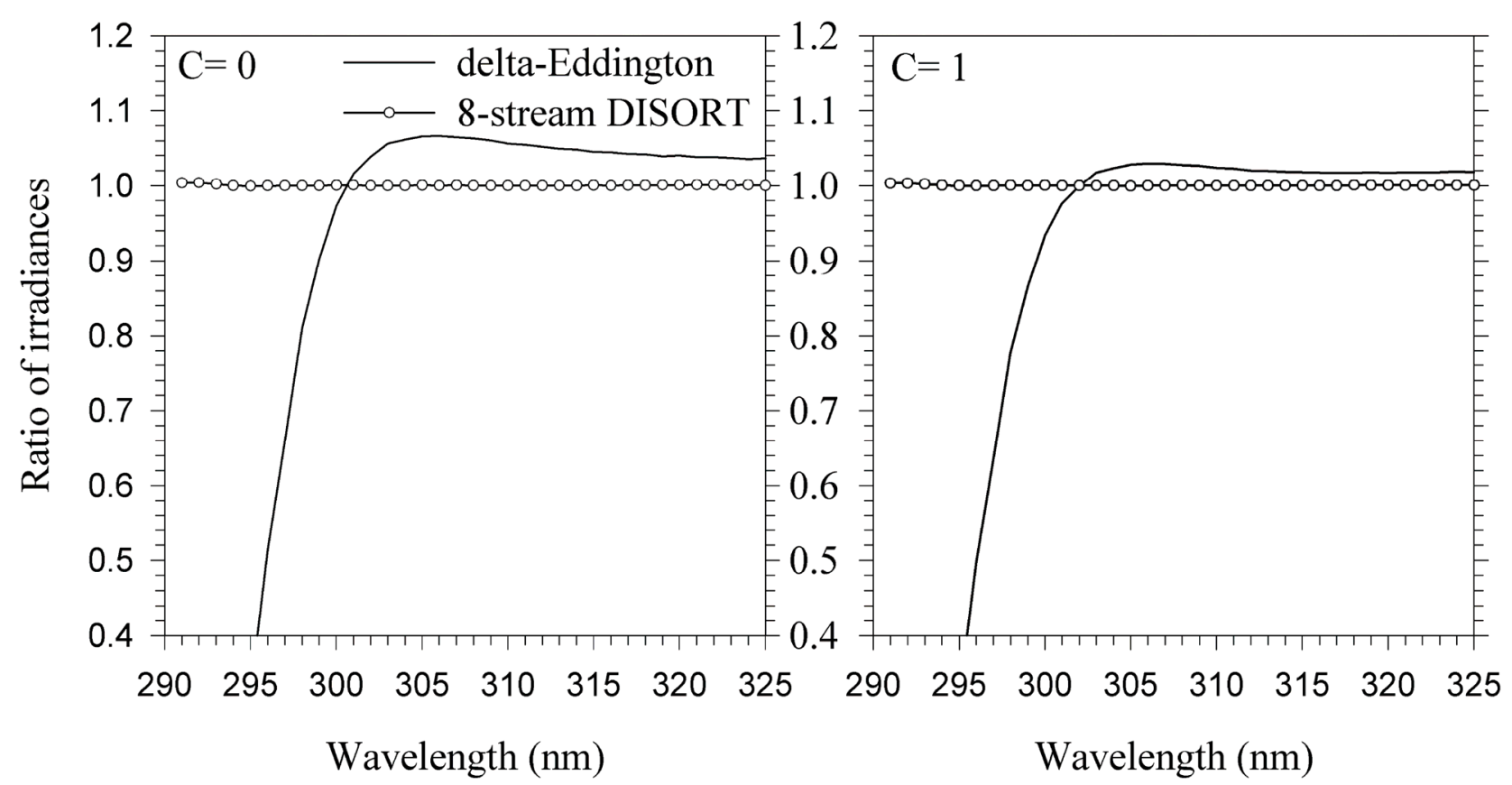

Figure 2. Ratio of spectral irradiance calculated by delta-Eddington and 8-stream DISORT methods to that of 16-stream DISORT method for solar zenith angle of $64.4^{\circ}$ for clear $(C=0)$ and overcast $(C=1)$ sky conditions for Toronto on June 24 , 1993 with $302 \mathrm{DU}$ total ozone column and a surface albedo of 0.05 .

(MBE), which measures systematic error, and the root mean square error (RMSE), which includes both systematic and non-systematic error [39]. When MBE is small, the RMSE measures mainly the non-systematic error. If $d_{i}$ is the difference between calculated and measured irradiances (daily or monthly), MBE and RMSE are defined from the variance of $d$

$$
\sigma_{d}^{2}=\frac{\sum d_{i}^{2}}{N}-\left(\frac{\sum d_{i}}{N}\right)^{2}=(\mathrm{RMSE})^{2}-(\mathrm{MBE})^{2},
$$

where $N$ is the number of data points. The performance measures are expressed as percentages of the mean measured irradiance for the relevant period.

The main source of random error stems from the cloud cover data. Since cloud cover is only reported once an hour, cloudiness variations between hours are missed. Linear interpolation of cloud cover for the Brewer instrument's measurement time only improves the validity of cloud estimates if the real variation of cloudiness between hourly observations is linear. Intuitively, errors arising from interpolation are expected to be random although initial errors in observer cloud estimates are probably systematic since observers tend to overestimate cloud cover because the earth curvature leads to an impression of greater cloudiness toward the horizon in non-overcast sky conditions [40].

\subsection{Comparisons of Irradiances from the Delta-Eddington and DISORT Methods}

The numerical experiments by Forster and Shine [8] revealed systematic overestimation by the delta-Eddington method. Here, their analysis has been applied to a real atmosphere (June 24, 1993 at Toronto) for both cloudless and overcast skies.

Figure 2 shows ratios of spectral irradiances calculated by both the delta-Eddington and 8-stream DISORT methods to irradiances calculated by a 16 -stream DISORT method for a solar zenith angle of $64.4^{\circ}$, as used by Forster and Shine [8]. The DISORT ratio is close to one at all wavelengths in both cloud cases while, the delta-Eddington values decrease rapidly below $302 \mathrm{~nm}$. The delta-Eddington model agrees to within $2 \%$ with DISORT for the overcast case at wavelengths greater than $302 \mathrm{~nm}$ but the error increases to $7 \%$ for the cloudless sky cases, respectively, at $305 \mathrm{~nm}$. Delta-Eddington values also fall off sharply for wavelengths below about $300 \mathrm{~nm}$ in both cloudless and overcast cases.

Figure 3 compares ratios of delta-Eddington to 8stream DISORT spectral irradiances at seven solar zenith angles for the June 24, 1993 atmosphere and simulated cloudless and overcast skies. In the cloudless case, the delta-Eddington method generally overestimates spectral irradiances at wavelengths greater than $305 \mathrm{~nm}$ and underestimates it at wavelengths below $300 \mathrm{~nm}$ at solar ze- 


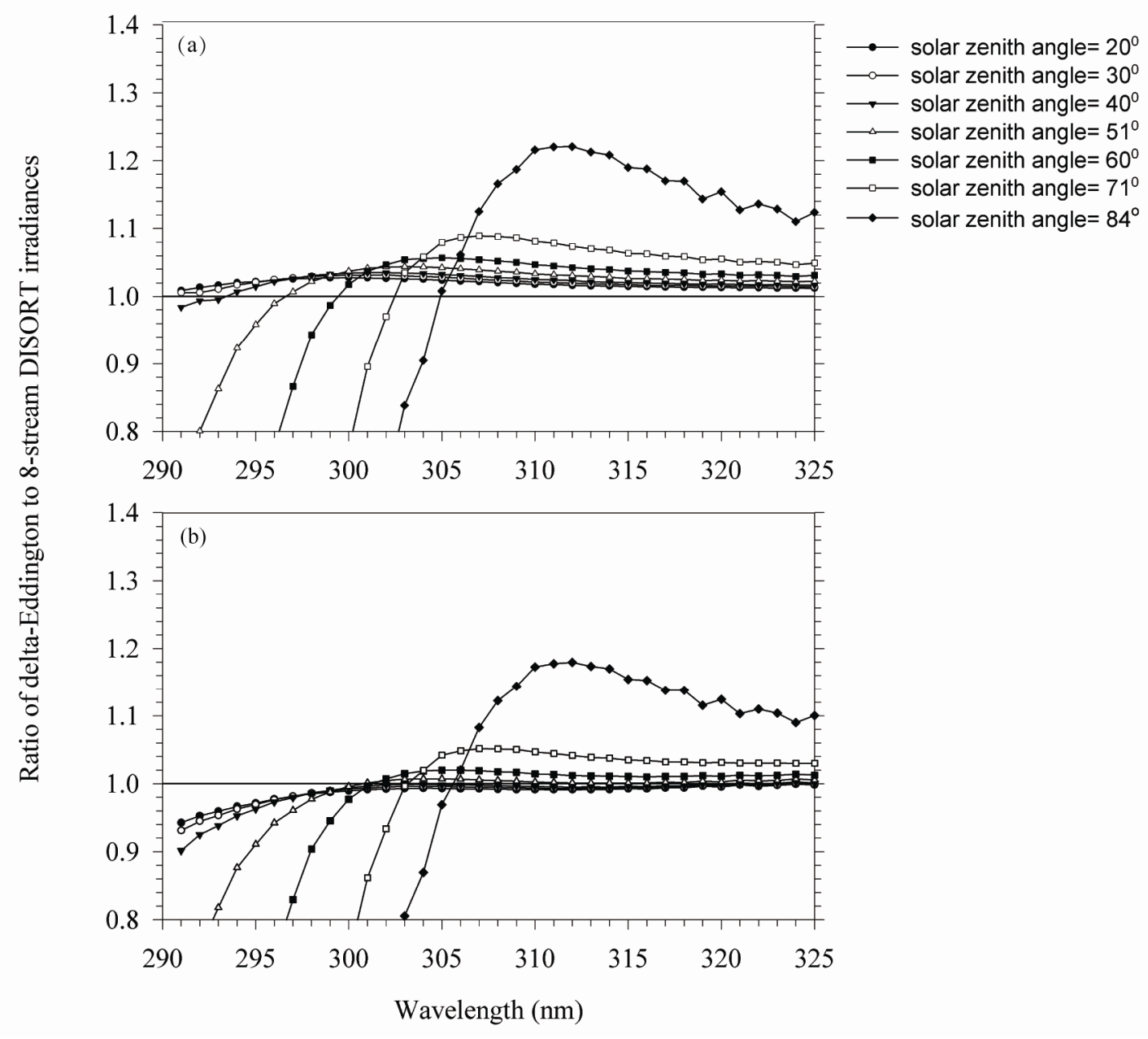

Figure 3. Ratio of spectral irradiance calculated by delta-Eddington and 8-stream DISORT method for solar zenith angle of $64.4^{\circ}$ for clear $(C=0)$ and overcast $(C=1)$ sky conditions for Toronto on June 24, 1993 with 302 DU total ozone column and a surface albedo of 0.05 .

nith angles greater than $60^{\circ}$. In the overcast case, deltaEddington estimates are closer to DISORT values except at smaller wavelengths (below $302 \mathrm{~nm}$ ) at larger solar zenith angles (greater than $50^{\circ}$ ). Also, the irradiance drop below unity increases for larger solar zenith angles and with overcast. Figures 2 and $\mathbf{3}$ show that the delta-Eddington method can be expected to overestimate spectral irradiances at most wavelengths in most cases.

At large solar zenith angles and shorter wavelengths (less than $305 \mathrm{~nm}$ ) where ozone absorption is high, the delta-Eddington method did not perform well because of the truncation of the scattering phase function to two terms. Forster and Shine [8] showed that this also applies to a two stream DISORT. Although the amount of irradiance is very small at these short wavelengths it may nevertheless be important because this is the portion of the spectrum where biological sensitivities are maximum for many processes. Therefore, the 8-stream DISORT method should be used for spectral irradiances at wavelengths below $305 \mathrm{~nm}$.

Figure 4 shows the variation of the ratio of irradiances of the delta-Eddington and 8-stream DISORT methods with ozone amount and sun angle for cloudless and overcast conditions at $295 \mathrm{~nm}$ and $305 \mathrm{~nm}$. At $295 \mathrm{~nm}$, the delta-Eddington error increases strongly with ozone amount, especially at larger solar zenith angles (greater than $50^{\circ}$ ). Cloud reduces the range of the ratio values and they never exceed unity. At $305 \mathrm{~nm}$, the delta-Eddington error depends only slightly on ozone except at solar zenith angles larger than $70^{\circ}$. Under overcast, the ratio range is mainly between 1 and 1.05 except at a zenith angle of $84^{\circ}$ where it is similar to the cloudless ratio at the same angle. Therefore, for wavelength $\geq 305 \mathrm{~nm}$, and when considering daily total spectral irradiances, errors in the delta-Eddington approximation are less important. This is because the times of day with smaller solar zenith 


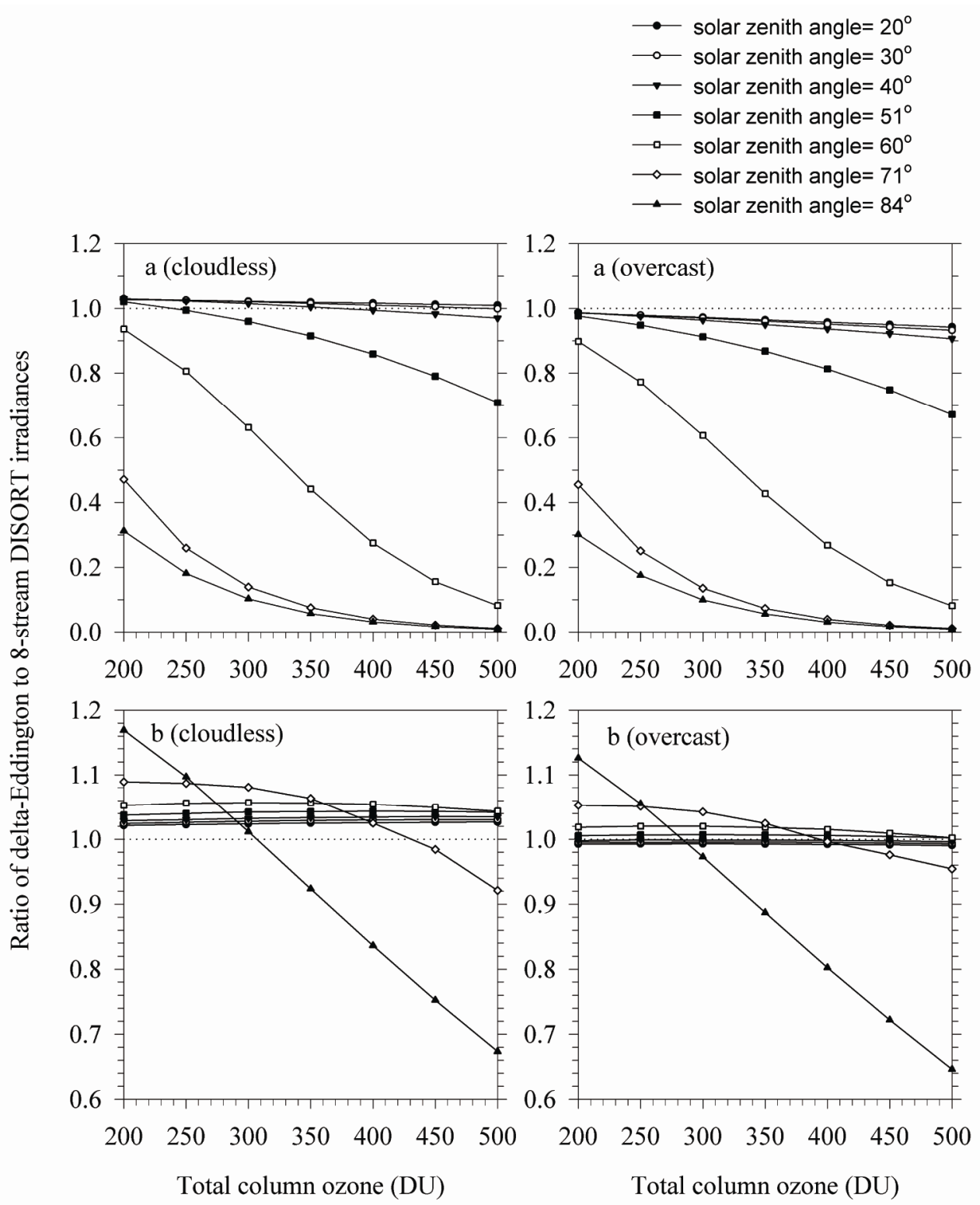

Figure 4. Ratio of irradiances calculated by delta-Eddington method to 8-stream DISORT method as a function of total column ozone and solar zenith angle for a wavelength of $295 \mathrm{~nm}(\mathrm{a})$ and $305 \mathrm{~nm}$ (b) for Toronto on June 24, 1993 for cloudless and overcast sky conditions with a surface albedo of 0.05 .

angles contribute most to the total irradiances.

Daily values of spectral and broadband irradiances from the delta-Eddington and DISORT models were compared for all sky conditions using annual values of cloud optical depth for each station showed in Table 1 [37].

Seven wavelengths $(295,300,305,310,315,320$ and $325 \mathrm{~nm}$ ) were selected to demonstrate model spectral performance for Resolute, Churchill, Winnipeg and Toronto for 1993. Table 2 shows MBE and RMSE for 295 $\mathrm{nm}$ and $305 \mathrm{~nm}$. Statistics for $300 \mathrm{~nm}$ are similar to those for $295 \mathrm{~nm}$ and statistics for all other wavelengths are similar to those for $305 \mathrm{~nm}$ and therefore are not shown. In general, the delta-Eddington irradiances exceed DISORT's values by $3-7 \%$ with the exception of Resolute at $295 \mathrm{~nm}$. RMSE values are mainly within $3-14 \%$. These differences are within the uncertainty of the Brewer instrument $( \pm 10 \%)$ and are smaller than the differences between irradiances measured with different instruments [41-43].

Resolute is an exception. At $295 \mathrm{~nm}$, delta-Eddington underestimates irradiance by $23 \%$. This is attributed to high cloudiness and large solar zenith angles (Figure 3). Forster and Shine [8] have shown that the delta-Edding- 
Table 1. Characteristics of the inferred cloud optical depth for the nine Canadian datasets. $\mathbf{N}$ is the number of data points.

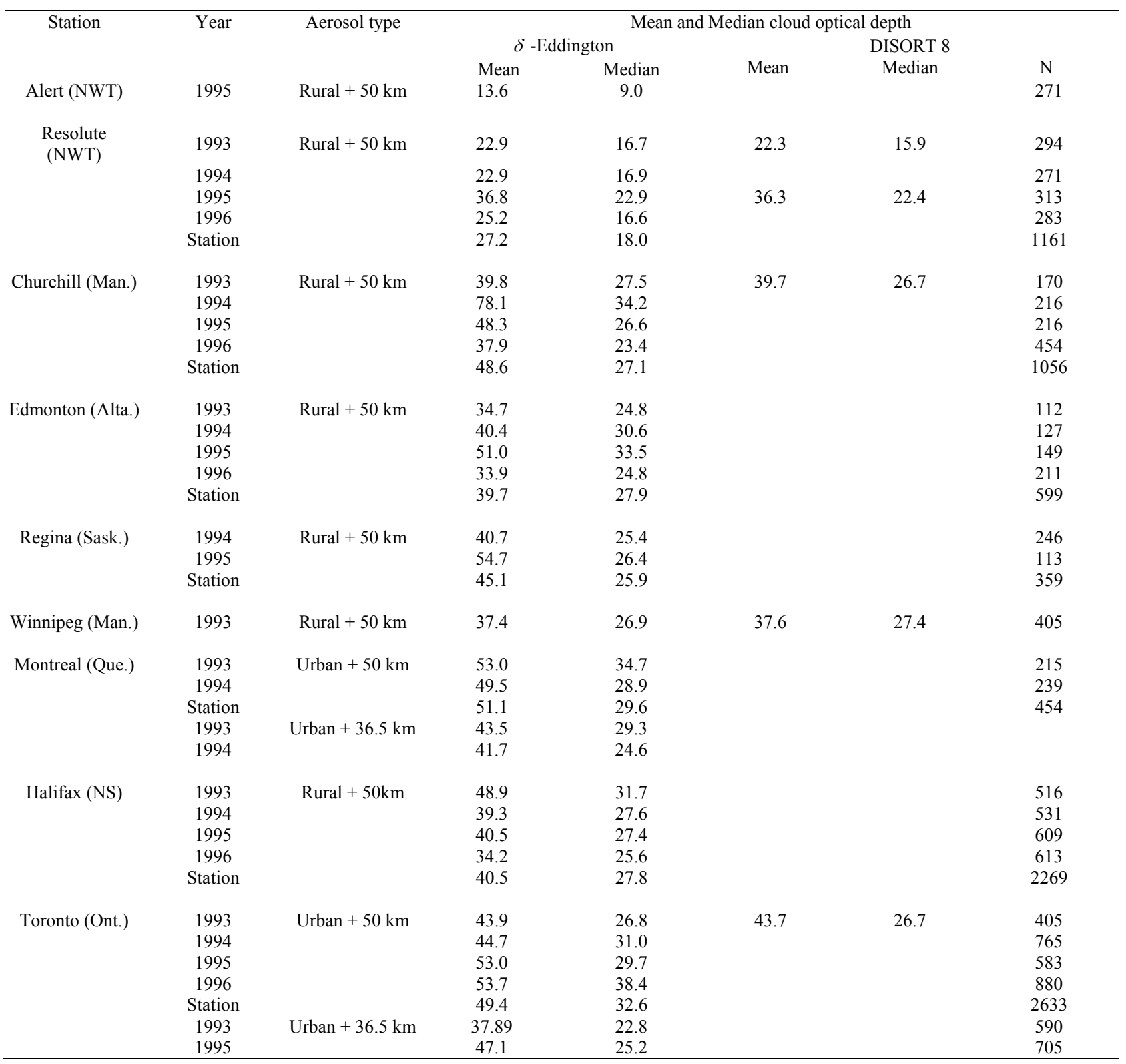

Table 2. Comparison of daily spectral irradiances from the delta-Eddington and 8-stream DISORT methods for the period indicated for each station. $N$ is the number of data points and $\bar{M}$ is the mean annual daily spectral irradiance calculated

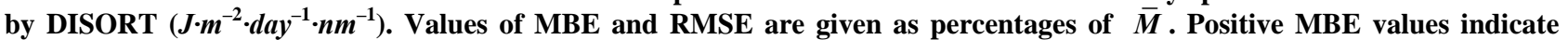
delta-Eddington overestimation.

\begin{tabular}{|c|c|c|c|c|}
\hline Statistics & Resolute Bay 1993 & Churchill 1993 & Winnipeg 1993 & Toronto 1993 \\
\hline \multicolumn{5}{|c|}{295 nm } \\
\hline$N$ & 89 & 136 & 136 & 192 \\
\hline $\bar{M}$ & 0.07 & 0.46 & 0.83 & 1.37 \\
\hline MBE & -23.00 & 6.92 & 5.72 & 6.61 \\
\hline RMSE & 26.44 & 13.94 & 9.00 & 10.25 \\
\hline \multicolumn{5}{|c|}{305 nm } \\
\hline$N$ & 141 & 178 & 228 & 250 \\
\hline $\bar{M}$ & 180.45 & 347.49 & 370.41 & 474.93 \\
\hline MBE & 7.40 & 3.71 & 3.15 & 3.31 \\
\hline RMSE & 11.11 & 3.26 & 3.32 & 4.41 \\
\hline
\end{tabular}




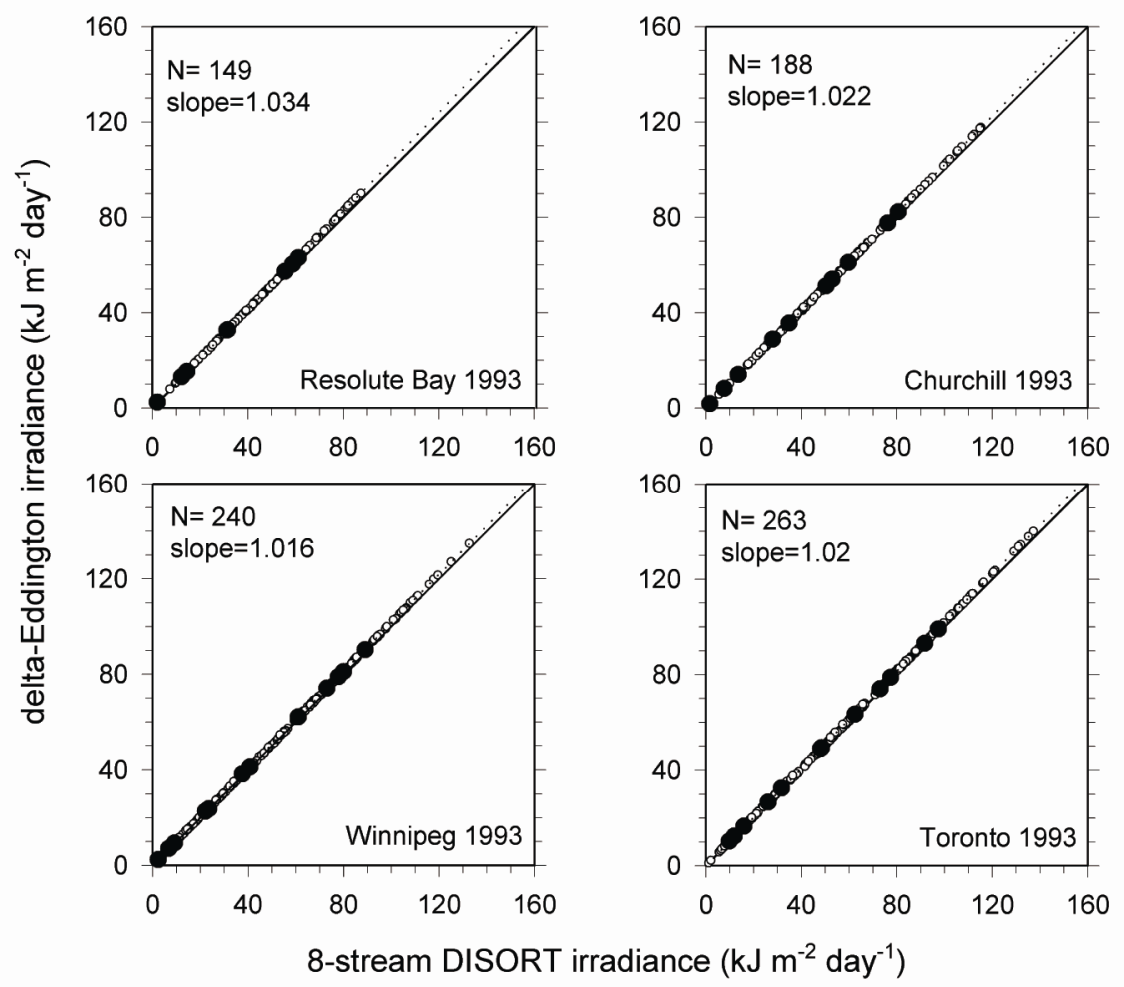

Figure 5. Comparison of 8-stream DISORT and delta-Eddington daily totals (white circles) and monthly averages (black circles) broadband irradiances using annual values of cloud optical depth for each station (Table 1) at Resolute Bay, Churchill, Winnipeg and Toronto. The dotted lines represent linear regressions constrained to pass through the origin.

ton method underestimates the multiple scattering of cloud by up to $14 \%$. The underestimation is not apparent at the lower latitude stations where cloudiness is less and sun angles are higher.

For broadband irradiances, Forster and Shine [8] showed for a theoretical atmosphere that the average delta-Eddington transmittance exceeds 16 stream DISORT estimates by $5 \%$ at a sun angle of $60^{\circ}$. We confirm this for real atmospheres for 1993 at Resolute, Churchill, Winnipeg and Toronto (Figure 5) using 8-stream DISORT. The overestimates are less than $4 \%$. The irradiances represent the wide range of solar zenith angles and sky conditions found in midlatitude, subarctic and arctic stations.

\subsection{Comparisons of Model Calculations with Measurements}

\subsubsection{Spectral Results}

Comparison statistics of daily spectral irradiances between models and measurements is given in Table $\mathbf{3}$ for the two wavelengths (295 nm and $305 \mathrm{~nm}$ used previously) for one year at nine stations. For wavelengths $\geqq$ $305 \mathrm{~nm}$ the MBE for the two methods is mainly within $5 \%$ of the mean measured irradiance. This is well within the uncertainty of the Brewer instrument. Biases for delta-Eddington are mainly positive while those for DISORT are mainly negative. This follows from section 5.2 which showed that the delta-Eddington method, generally, produces larger spectral irradiances than DISORT. The better MBE for delta-Eddington (the inferior model) at longer wavelengths may suggest systematic overestimation by Brewer instruments.

The comparisons between model estimates and measurements are poorer at wavelengths below $305 \mathrm{~nm}$ although DISORT estimates match measurements closer than the delta-Eddington estimates as expected (Table 3). The larger magnitude of the MBE values at $295 \mathrm{~nm}$ at most stations for both models may be attributed in part to the difficulty in measuring within this spectral region. In this range, very low light levels and increased stray light scattering increase the instrumental uncertainty (E. Wu of MSC, personal communication, 2007).

Delta-Eddington's rapid decrease in irradiance at 295 $\mathrm{nm}$, shown in section 5.2, is only detectable at the arctic stations as a result of the greater cloudiness and solar zenith angles. At the other stations, except Halifax, deltaEddington's MBE values are positive. This follows from flux overestimation in cloudless skies that are more common than in the arctic (Figure 3). At Halifax, the 
Table 3. Comparison of daily spectral irradiances from the delta-Eddington (DE) and 8-stream DISORT (D8) methods against measurements for the period indicated for each station. $N$ is the number of data points and $\bar{M}$ is the mean an-

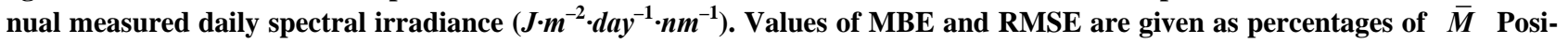
tive MBE alues indicate model overestimation.

\begin{tabular}{|c|c|c|c|c|c|c|c|c|c|}
\hline Statistics & Alert 1995 & Resolute 199 & 95 Churchill 1993 & $\begin{array}{c}\text { Edmonton } \\
1994\end{array}$ & Regina 1994 & $\begin{array}{c}\text { Winnipeg } \\
1993\end{array}$ & Montreal 1994 & Halifax 1993 & Toronto 1993 \\
\hline \multicolumn{10}{|c|}{$295 \mathrm{~nm}$} \\
\hline$N$ & 12 & 80 & 136 & 135 & 204 & 136 & 154 & 206 & 192 \\
\hline $\bar{M}$ & 0.02 & 0.05 & 0.46 & 0.62 & 0.84 & 0.84 & 0.72 & 0.80 & 1.25 \\
\hline MBE (DE) & -39.93 & -3.54 & 5.25 & 71.62 & 1.99 & 10.50 & 43.94 & -12.31 & 20.22 \\
\hline MBE (D8) & 33.46 & 24.46 & -1.21 & 51.60 & -9.06 & -0.42 & 27.90 & -19.67 & 9.41 \\
\hline RMSE (DE) & 85.71 & 88.09 & 51.14 & 87.31 & 49.19 & 32.28 & 70.22 & 45.18 & 38.84 \\
\hline RMSE (D8) & 64.40 & 90.81 & 51.47 & 75.81 & 45.56 & 34.21 & 51.34 & 51.89 & 32.08 \\
\hline \multicolumn{10}{|c|}{$305 \mathrm{~nm}$} \\
\hline$N$ & 31 & 154 & 178 & 274 & 211 & 228 & 212 & 231 & 250 \\
\hline $\bar{M}$ & 121.09 & 155.68 & 355.85 & 340.43 & 497.54 & 405.60 & 475.38 & 425.44 & 494.14 \\
\hline MBE (DE) & -1.88 & 14.37 & 5.72 & 5.07 & 5.23 & -1.26 & 0.28 & -6.15 & 2.85 \\
\hline MBE (D8) & -11.58 & 7.85 & -2.35 & -2.15 & -1.73 & -6.68 & -6.39 & -10.68 & -3.89 \\
\hline RMSE (DE) & 26.69 & 23.50 & 25.11 & 25.08 & 20.13 & 14.18 & 12.82 & 13.76 & 11.83 \\
\hline RMSE (D8) & 29.50 & 25.30 & 23.28 & 20.18 & 17.77 & 18.40 & 13.14 & 17.55 & 12.15 \\
\hline
\end{tabular}
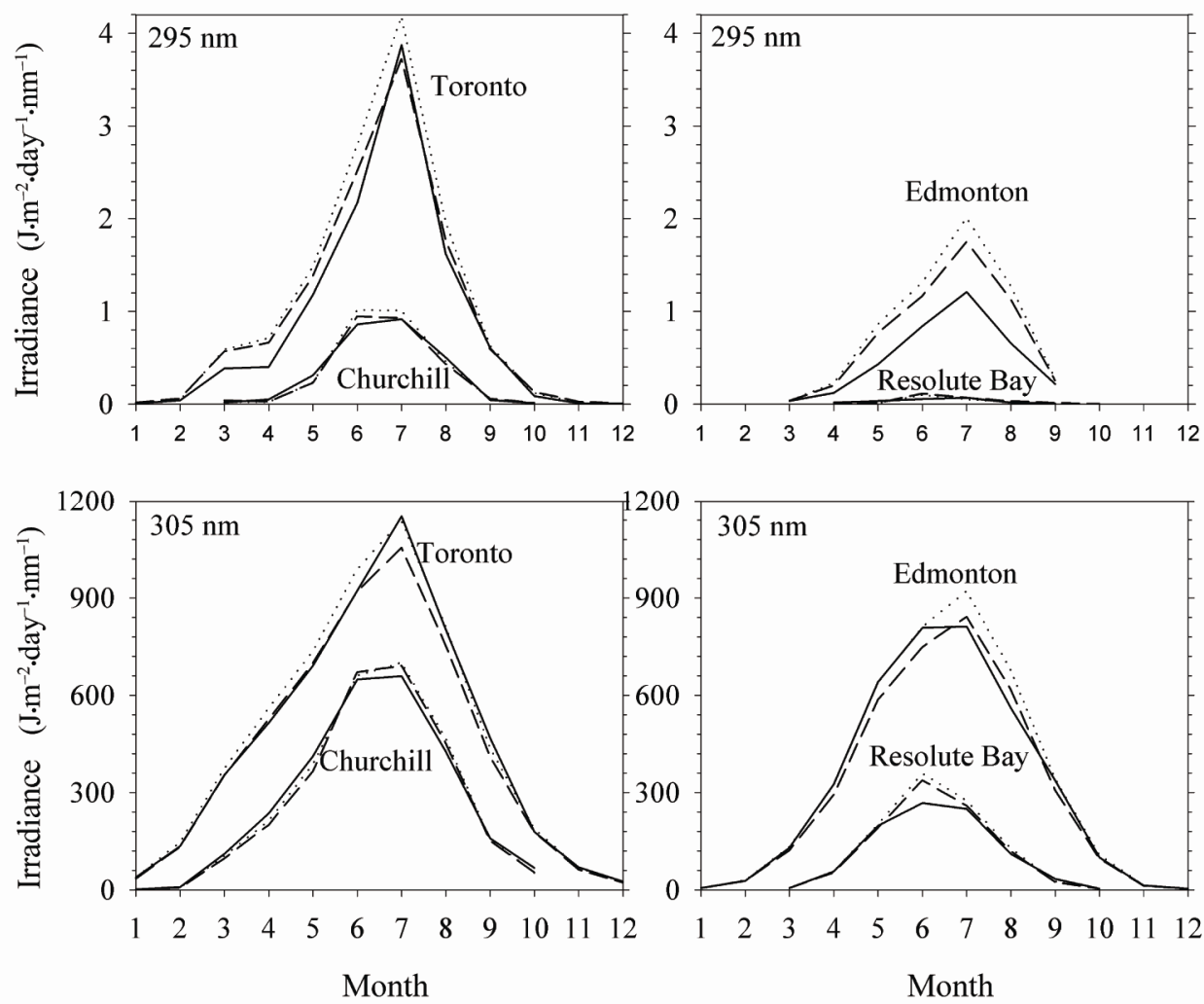

Figure 6. Mean monthly measured (solid lines) and calculated by delta-Eddington (dotted lines) methods spectral irradiance at 295, $305 \mathrm{~nm}$ for Toronto in 1993, Edmonton in 1994 and Resolute Bay in 1995.

negative MBE for both models suggests a systematic error in the Brewer instrument.

RMSE values for wavelengths greater than $300 \mathrm{~nm}$ are mainly within $12 \%$ to $25 \%$. These decrease with length of averaging period for both models to below $10 \%$ for 30-day averaging periods, which is similar to decreases for broadband solar radiation estimates [44].
Mean monthly measured and calculated spectral irradiances for $295 \mathrm{~nm}$ and $305 \mathrm{~nm}$ are plotted for four stations (Resolute, Churchill, Edmonton and Toronto) in Figure 6. Both model estimates follow measurements well but at $295 \mathrm{~nm}$ the delta-Eddington method consistently overestimates irradiances.

Figure 7 shows the annual variation of measured and 


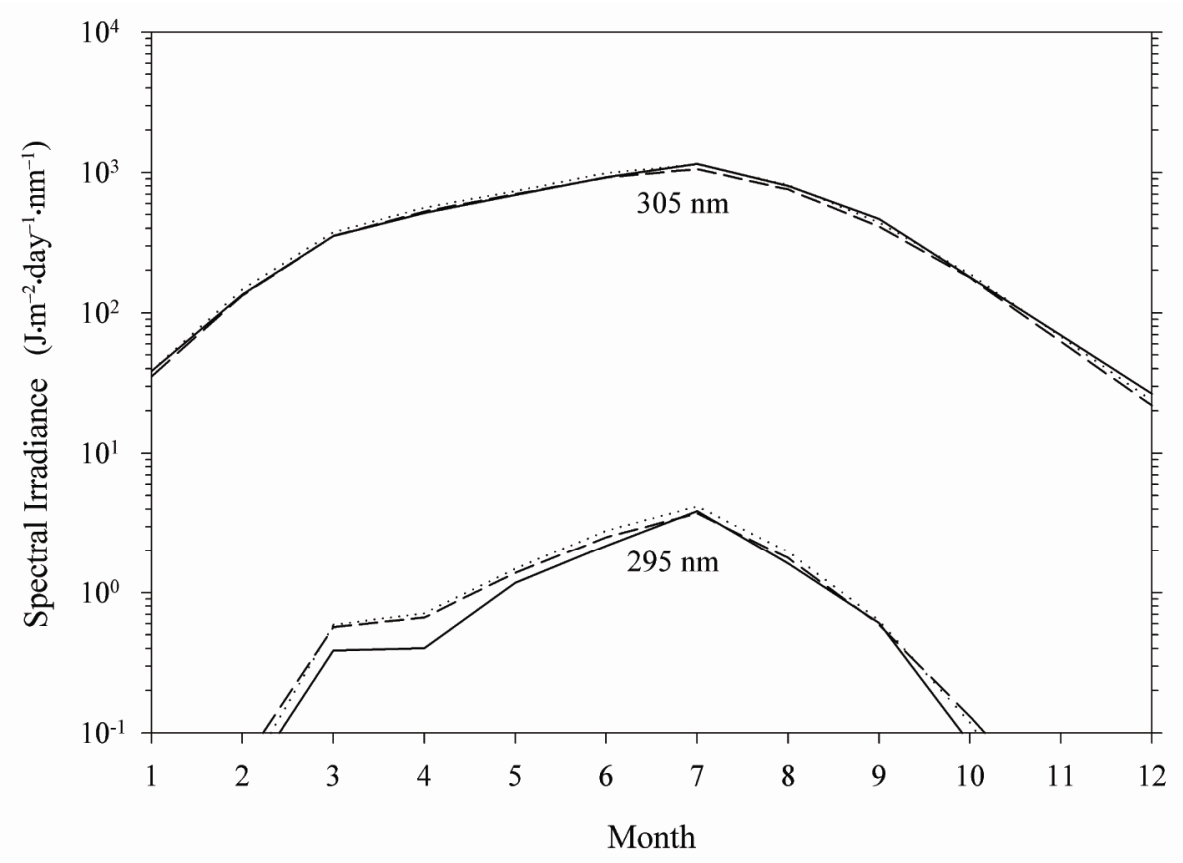

\begin{tabular}{lrllllll}
\hline & \multicolumn{4}{c}{ Delta-Eddington } & \multicolumn{2}{l}{ DISORT 8 } \\
\hline Wavelength & \multicolumn{1}{c}{$M$} & Slope & MBE\% & RMSE\% & Slope & MBE\% & RMSE\% \\
\hline $295 \mathrm{~nm}$ & 0.87 & 1.207 & 20.70 & 30.39 & 1.103 & 10.29 & 18.47 \\
$305 \mathrm{~nm}$ & 446.02 & 1.030 & 2.97 & 6.56 & 0.962 & -3.83 & 8.02 \\
\hline
\end{tabular}

Figure 7. Mean monthly measured (solid lines) spectral and calculated by the delta-Eddington (dotted lines) and DISORT (dash lines) models for various wavelengths for Toronto 1993. Table gives relative MBE and RMSE values with positive MBE indicating model overestimation. $M$ is the mean monthly measured irradiance.

modeled spectral irradiances for $295 \mathrm{~nm}$ and $305 \mathrm{~nm}$ for Toronto 1993. The table below Figure 7 indicates larger MBE and RMSE at $295 \mathrm{~nm}$. Both models perform well at wavelengths $305 \mathrm{~nm}$ with greatly reduced MBE and RMSE.

Figure 8 shows mean monthly measured spectral irradiance and corresponding model values with both linear and logarithmic plots for three months (January, March and June) for Edmonton in 1994, Halifax in 1993 and Toronto in 1993. The linear plot illustrates more clearly the agreement of measured and calculated irradiances at larger wavelengths while the logarithmic plot is better for showing the agreement at smaller wavelengths. Model values follow measurements well except below $300 \mathrm{~nm}$. This may be attributable as stated earlier to the difficulty of measuring such low irradiance levels and to the light leakage problem even though a correction has been applied to irradiances for wavelengths less than 305 $\mathrm{nm}$ [23]. Model calculations show the same spectral variation as the Brewer measurements at wavelengths greater than $295-298 \mathrm{~nm}$. The Halifax and Toronto data show evidence of stray light leakage in the corrected Brewer measurements.

\subsubsection{Broadband Results}

Performance statistics for daily total and monthly averaged broadband irradiances are given in Table 4 for one year at nine stations. In general, both models perform well for broadband calculations with MBE mainly less than $5 \%$ and RMSE less than $25 \%$, which is similar to values obtained from comparisons for global irradiance [45] and the preliminary UV-B irradiance study for Canadian stations by Davies et al. [7]. This comparison shows that the delta-Eddington algorithm is adequate for estimating surface broadband UV-B irradiance under all sky conditions from mid-latitudes to the arctic. The method is faster computationally than the DISORT algorithm. Three sets of irradiances were calculated and compared to show the sensitivity of the model to $\tau_{c}$. Daily and monthly broadband irradiances from deltaEddington algorithm were calculated separately using (a) annual $\tau_{c}$ for each station, (b) one $\tau_{c}$ for each station, and (c) one $\tau_{c}$ for all non-arctic stations. Agreement in all three cases is good and the results are very similar. MBE is less than $7 \%$ and daily RMSE less than $25 \%$, decreasing to less than $15 \%$ for monthly averages 

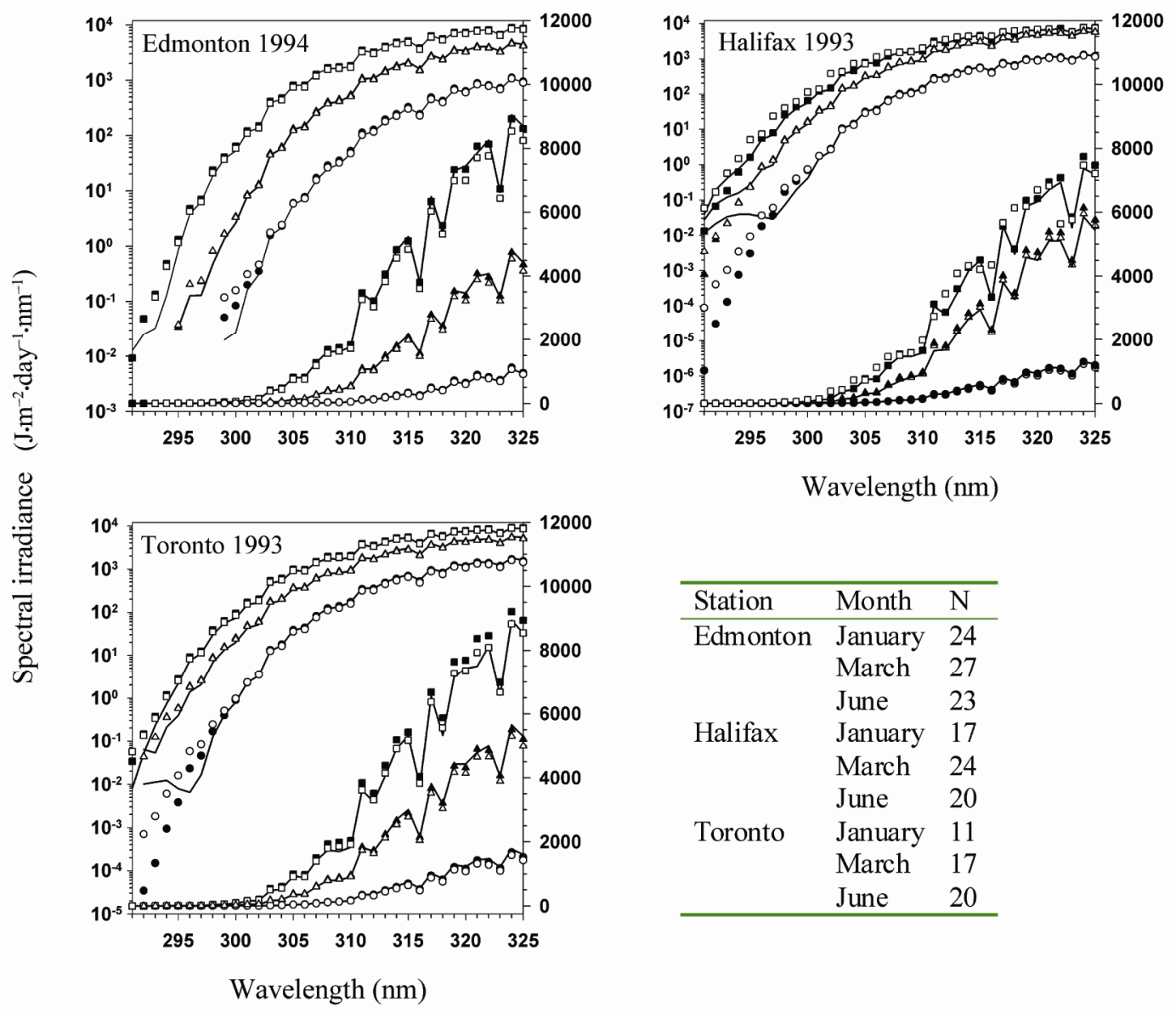

\begin{tabular}{lll}
\hline Station & Month & $\mathrm{N}$ \\
\hline Edmonton & January & 24 \\
& March & 27 \\
& June & 23 \\
Halifax & January & 17 \\
& March & 24 \\
& June & 20 \\
Toronto & January & 11 \\
& March & 17 \\
& June & 20 \\
\hline
\end{tabular}

Figure 8. Mean monthly measured (solid lines) and calculated by delta-Eddington (Black circles, triangles and squares) and 8-stream DISORT (white circles, triangles and squares) spectral irradiance on a logarithmic (upper lines, left axis) and linear (lower lines, right axis) scale for January (circles), March (triangles) and June (squares) for Edmonton in 1994, Halifax in 1993 and Toronto in 1993. Table gives $\mathrm{N}$ which is the number of days used for each month.

Table 4. Summary of delta-Eddington (DE) and 8-stream DISORT (D8) performance measures against measurements for daily total and monthly averaged broadband irradiances for the period indicated for each station. $N$ is the number of data points and $\bar{M}$ is the mean annual measured daily total irradiance $\left(K J \cdot m^{-2} \cdot d a y^{-1}\right)$. Values of MBE and RMSE are given aspercentages (italic) of $\bar{M}$. Positive MBE values indicate model overestimation.

\begin{tabular}{|c|c|c|c|c|c|c|c|c|c|}
\hline Statistics & $\begin{array}{l}\text { Alert } \\
1995\end{array}$ & $\begin{array}{c}\text { Resolute } \\
1995\end{array}$ & $\begin{array}{c}\text { Churchill } \\
1993\end{array}$ & $\begin{array}{c}\text { Edmonton } \\
1994\end{array}$ & $\begin{array}{c}\text { Regina } \\
1994\end{array}$ & $\begin{array}{c}\text { Winnipeg } \\
1993\end{array}$ & $\begin{array}{c}\text { Montreal } \\
1994\end{array}$ & $\begin{array}{c}\text { Halifax } \\
1993\end{array}$ & $\begin{array}{c}\text { Toronto } \\
1993 \\
\end{array}$ \\
\hline \multicolumn{10}{|c|}{ Daily total } \\
\hline$N$ & 31 & 154 & 178 & 274 & 211 & 228 & 212 & 231 & 250 \\
\hline $\bar{M}$ & 38.26 & 51.28 & 60.32 & 49.66 & 63.23 & 54.14 & 62.66 & 54.80 & 60.15 \\
\hline MBE (DE) & -0.45 & 3.13 & -0.47 & 5.55 & 6.30 & 3.73 & -1.19 & -1.10 & 1.92 \\
\hline MBE (D8) & -7.59 & -0.98 & -5.95 & -0.50 & 0.57 & -1.52 & -7.07 & -5.75 & -2.96 \\
\hline RMSE (DE) & 23.24 & 11.37 & 18.09 & 19.21 & 16.58 & 13.34 & 14.33 & 17.76 & 14.78 \\
\hline RMSE (D8) & 24.67 & 11.30 & 18.78 & 15.88 & 14.25 & 12.60 & 15.18 & 18.94 & 14.61 \\
\hline \multicolumn{10}{|c|}{ Monthly average } \\
\hline$N$ & 4 & 8 & 10 & 12 & 10 & 12 & 12 & 12 & 12 \\
\hline $\bar{M}$ & 38.27 & 39.76 & 49.09 & 46.33 & 55.02 & 47.79 & 50.17 & 52.18 & 55.81 \\
\hline $\operatorname{MBE}(\mathrm{DE})$ & -2.18 & 2.80 & -1.85 & 5.10 & 5.30 & 3.25 & -1.50 & -1.20 & 1.77 \\
\hline MBE (D8) & -9.02 & -1.51 & -7.31 & 0.91 & -0.49 & -2.00 & -7.53 & -5.88 & -3.21 \\
\hline RMSE (DE) & 10.64 & 8.13 & 14.15 & 10.41 & 9.37 & 5.34 & 6.79 & 9.28 & 4.88 \\
\hline RMSE (D8) & 15.14 & 6.55 & 15.23 & 7.49 & 5.86 & 3.79 & 10.00 & 11.59 & 5.35 \\
\hline
\end{tabular}



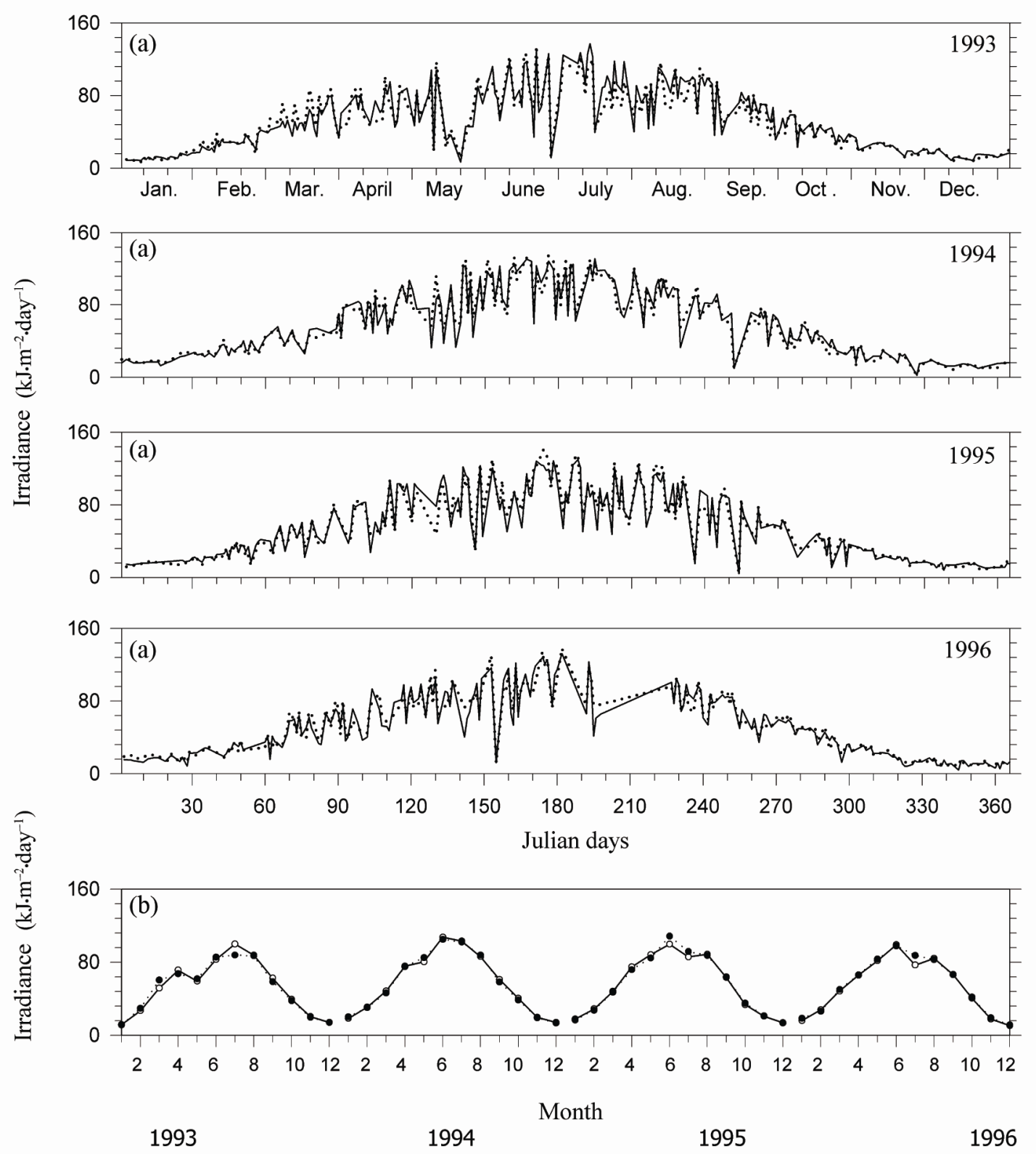

Figure 9. (a) Daily total measured (solid lines) and calculated (dotted lines) broadband irradiances for Halifax (1993-1996) and (b) Monthly average broadband irradiances measured (line and white circles) and calculated by delta-Eddington model (dotted and black circles) for Halifax for years 1993-1996.

(Table 5).

Binyamin et al. [37] showed that $\tau_{c}$ values for midlatitudes and subarctic showed little variation with latitude. Therefore, values of $\tau_{c}$ for non-arctic stations were combined to produce a pooled median value of 27 . Table 5 shows that on average the irradiance changes by less than $0.2 \%$ when this pooled median value is used. This agreement suggests that in this range of climate $\tau_{c}$ variation is similar and possibly representative of other midlatitudes and sub-arctic climates. This obviates the need for extensive computation to retrieve $\tau_{c}$ for each station and year.

An example of the daily variation in model performance is shown in Figure 9 for Halifax (1993-1996). Model irradiances follow the variation of measurements well with no indication of seasonal biases, which implies that a constant $\tau_{c}$ can be used satisfactorily. Figure 9 also shows the model performance of monthly averaged irradiance for Halifax. Most irradiances compare to within $10 \%$. Larger differences (up to $15 \%$ ) occur in a few summer months but they change in sign from year to year. Similar results were found by Norsang et al. [46] in 
Table 5. Summary of delta-Eddington performance measures for daily total and monthly average irradiances using annual $\tau_{c}$, station $\tau_{c}$ and pooled $\tau_{c} . N$ is the number of data points and $\bar{M}$ is the mean daily measured broadband irradiance $\left(\mathrm{kJ}^{-2} \cdot d a \mathrm{y}^{-1}\right)$. Values of MBE and RMSE are given as percentages of $\bar{M}$. Positive MBE values indicate model overestimation.

\begin{tabular}{|c|c|c|c|c|c|c|c|c|c|}
\hline Statistics & Alert & Resolute & Churchill & Edmonton & Regina & Winnipeg & Montreal & Halifax & Toronto \\
\hline & & & & Annual $\tau_{c}$ & & & & & \\
\hline \multicolumn{10}{|l|}{ Daily total } \\
\hline$N$ & 31 & 574 & 603 & 947 & 373 & 228 & 288 & 855 & 833 \\
\hline $\bar{M}$ & 38.26 & 47.09 & 58.51 & 51.47 & 58.79 & 54.14 & 66.12 & 57.57 & 66.05 \\
\hline MBE & -6.24 & -8.35 & -1.26 & -0.88 & -0.46 & -3.37 & -6.88 & -8.15 & -7.57 \\
\hline RMSE & 25.74 & 20.73 & 22.19 & 19.39 & 17.01 & 15.29 & 16.94 & 19.34 & 19.76 \\
\hline \multicolumn{10}{|c|}{ Monthly average } \\
\hline \multirow[t]{2}{*}{ RMSE } & 11.94 & 14.47 & 13.8 & 7.15 & 4.46 & 5.98 & 7.81 & 10.44 & 9.27 \\
\hline & & & & Station $\tau_{c}$ & & & & & \\
\hline \multicolumn{10}{|l|}{ Daily total } \\
\hline MBE & & -8.04 & -0.91 & -0.69 & 0.26 & & -6.35 & -8.02 & -8.33 \\
\hline RMSE & & 20.89 & 21.55 & 19.42 & 16.6 & & 16.63 & 19.19 & 20.13 \\
\hline \multicolumn{10}{|c|}{ Monthly average } \\
\hline \multirow[t]{2}{*}{ RMSE } & & 14.56 & 12.99 & 7.53 & 4.28 & & 7.16 & 10.27 & 9.57 \\
\hline & & & & Pooled $\tau_{c}$ & & & & & \\
\hline \multicolumn{10}{|l|}{ Daily total } \\
\hline MBE & & & -1.18 & -0.47 & -1.42 & -3.69 & -5.31 & -7.9 & -5.81 \\
\hline RMSE & & & 21.65 & 19.31 & 18.03 & 15.54 & 15.06 & 19.10 & 18.37 \\
\hline \multicolumn{10}{|c|}{ Monthly average } \\
\hline RMSE & & & 13.01 & 7.49 & 4.52 & 6.31 & 6.24 & 10.15 & 7.24 \\
\hline
\end{tabular}

Table 6. Comparisons between measured and calculated (delta-Eddington) daily total and monthly average broadband irradiances for two aerosols loading. $N$ is the number of data points and $\bar{M}$ is the mean measured irradiance $\left(\mathrm{kJ}^{\circ} \mathrm{m}^{-2} \cdot \mathrm{day} \mathrm{y}^{-1}\right)$. Values of MBE and RMSE are given as percentages of $\bar{M}$ Positive MBE values indicate model overestimation.

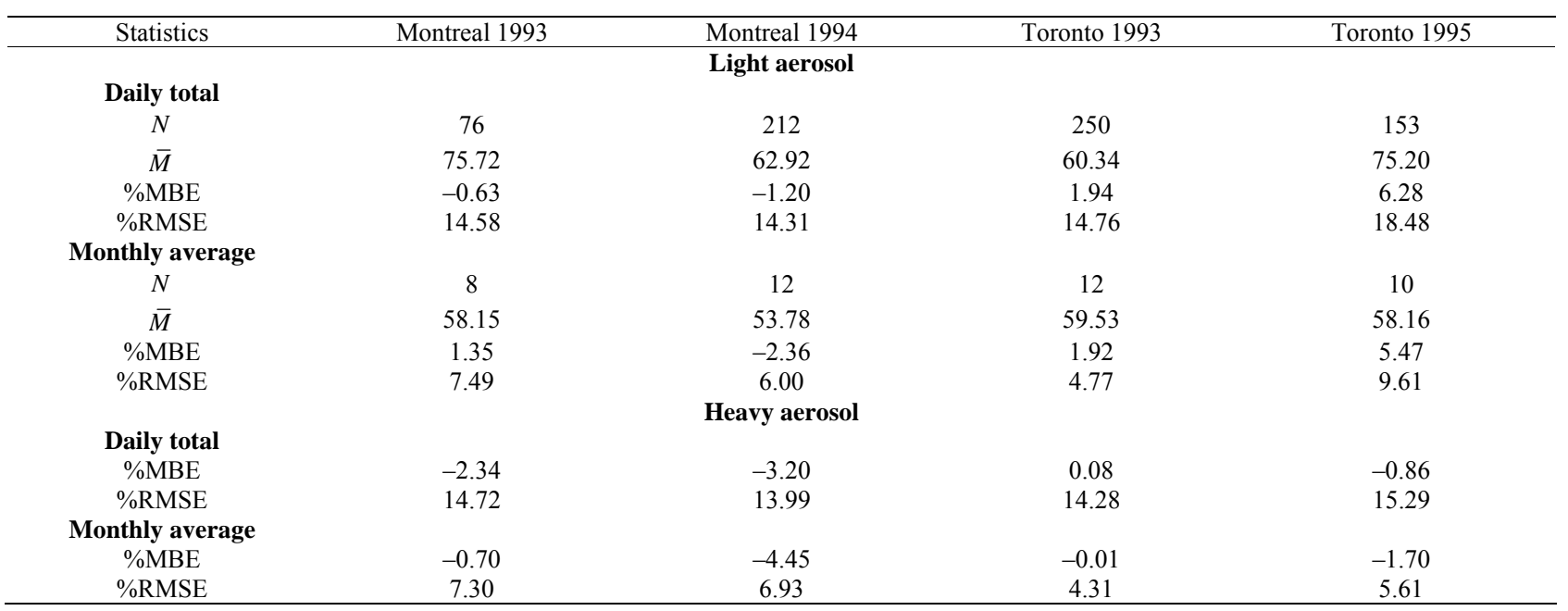

Lhasa, Tibet for clear sky irradiances.

\subsection{Comparisons of Two Different Aerosol Loadings}

In this section we show the effect of changing boundary layer aerosol from light (50 km visibility) to heavier (36.5 km visibility), which is the average of $50 \mathrm{~km}$ and $23 \mathrm{~km}$ models for Montreal (1993 and 1994) and Toronto (1993 and 1995). Separate values of $\tau_{c}$ were calculated for each station and year. The heavier aerosol reduced $\tau_{c}$ by an average of $15 \%$. Fluxes from the two urban aerosol loadings are compared with measurements at both stations. The heavier aerosol reduces irradiances by about $2 \%$ at Montreal and by $2-7 \%$ at Toronto (Table 6). This agrees well with the findings of Chertock et al. [47] and Wang et al. [48] who found that aerosols could reduce daily solar irradiance up to $3-5 \%$. For Montreal there is better agreement between the light aerosol model results and measurements with $\mathrm{MBE}$ less than 2.5\% for daily total and monthly average broadband irradiances (Table 6). For Toronto, the heavier aerosol model shows better agreement with MBE less than $2 \%$. 


\section{Conclusions}

This study evaluated the relative performance of the delta-Eddington and DISORT algorithms within a numerical model for estimating spectral and broadband UV-B irradiances for Canadian conditions and to validate model results with Brewer spectrophotometer measurements.

The most important findings are:

- The delta-Eddington method produces daily total spectral irradiances for all sky conditions, which are generally $3-7 \%$ larger than those from the 8 -stream DISORT method. The fractional overestimation decreases as wavelength increases. Irradiances are acceptable for wavelengths $\geq 305 \mathrm{~nm}$. This method is unsuitable for wavelengths below $305 \mathrm{~nm}$ where ozone absorption is high due to the truncation of the scattering phase function to two terms. At longer wavelengths its performance varies with solar zenith angle and cloudiness. For clear skies, the method always overestimates irradiances at all sun angles with the error increasing as the solar zenith angle increases. For cloudy skies the errors are much smaller.

- The delta-Eddington method performs very well for broadband calculations for both daily total and monthly averaged irradiances.

- Comparison of spectral estimates from both models with measurements indicate uncertainties in the Brewer measurements at wavelengths $<305 \mathrm{~nm}$.

- At wavelengths $\geq 305 \mathrm{~nm}$ better agreement with measurements by the delta-Eddington than by DISORT suggests overestimation by the Brewer spectrophotometer.

- Model estimates for broadband irradiances for both daily totals and monthly averages have a MBE less than $5 \%$ and RMSE less than $25 \%$ deceases to less than $15 \%$ for monthly averages. These statistics compare favourably with those obtained for global radiation [45].

- A constant $\tau_{c}$ value of 27 is adequate for all stations except the arctic. This is important because it suggests that further estimation of $\tau_{c}$ is not necessary.

- A light boundary layer aerosol model was suitable for Montreal and a heavy aerosol model for Toronto.

This research is the first to provide extensive evaluation for spectral and broadband irradiances for a large data set, which includes midlatitude, subarctic, and arctic stations. The spectral information is important to biologists who can combine it with various an action spectrum to determine potential biological exposure.

This physically-based model can be applied anywhere. Refinements to the extraterrestrial solar spectrum, Rayleigh scattering cross sections and ozone absorption coefficients are unlikely to be large and the model's lin- ear combination of cloudless and overcast components has been shown to work in a wide range of Canadian conditions. The greatest restriction to its use is the availability of cloud cover information. Future applications of the model should use satellite measurements of ozone and cloud.

The Brewer instrument data sets have not been corrected for the cosine error of the diffuser, temperature errors, as well as absolute radiometric calibration errors. In fact, the $6 \%$ increase made to the Brewer data in this study was an approximate correction to remove the systematic cosine error but the actual correction should be made depending on the solar zenith angle and sky illumination conditions [23].

\section{Acknowledgments}

We thank Dr. Hanna Maoh of University of Windsor for supplying Figure 1.

\section{References}

[1] J. E. Frederick, H. E. Snell and E. K. Haywood, "Solar Ultraviolet Radiation at the Earth'S Surface," Photochemistry and Phtobiology, Vol. 50, No. 4, 1989, pp. 443-450. doi:10.1111/j.1751-1097.1989.tb05548.x

[2] L. T. Molina and M. J. Molina, "Absolute Absorption Cross Sections of Ozone in the 185-350 um Wavelength Range," Journal of Geophysical Research, Vol. 91, No. D13, 1986, pp. 14501-14508. doi:10.1029/JD091iD13p14501

[3] D. Lubin, B. G. Mitchell, J. E. Frederick, A. D. Albert's, C. R. Booth, T. Lucas and D. Neuschuler, "A Contribution toward Understanding the Biospherical Significance of Antarctic Ozone Depletion," Journal of Geophysical Research, Vol. 97, 1992, pp. 7817-7827.

[4] S.-C. Tsay and K. Stamnes, "Ultraviolet Radiation in the Arctic: The Impact of Potential Ozone Depletions and Cloud Effects," Journal of Geophysical Research Atmospheres, Vol. 97, 1992, pp. 7829-7840.

[5] P. Wang and J. Lenoble, "Comparison between Measurements and Modeling of UV-B Irradiance for Clear Sky: A Case Study," Applied Optics, Vol. 33, No. 18, 1994, pp. 3964-3971. doi:10.1364/AO.33.003964

[6] P. M. de F. Forster, K. P. Shine and A. R. Webb, "Modelling Ultraviolet Radiation at the Earth'S Surface. PART II: Model and Instrument Comparison," Journal of Applied Meteorology, Vol. 34, No. 11, 1995, pp. 2426-2439.

[7] J. Davies, P. Kuhn, G. Duhamel, J. Binyamin and K. Runnalls, "An Ultraviolet (290 to $325 \mathrm{~nm}$ ) Irradiation Model for Southern Canadian Conditions," Physical Geography, Vol. 21, No. 4, 2000, pp. 327-344.

[8] P. M. de F. Forster and K.P. Shine, "A Comparison of Two Radiation Schemes for Calculating Ultraviolet Radiation," Quarterly Journal of Royal Meteorological Society, Vol. 121, No. 525, 1995, pp. 1113-1131. 
[9] W. J. Wiscombe and J. H. Joseph, "The Range of Validity of the Eddington Approximation," Icarus, Vol. 32, No. 3, 1977, pp. 262-377. doi:10.1016/0019-1035(77)90008-2

[10] J. Lenoble, “Atmospheric Radiative Transfer,” A. Deepak Pubulishing, Hampton, 1993, p. 176.

[11] C. Erlick and J. E. Frederick, "Effects of Aerosols on the Wavelength Dependence of Atmospheric Transmission in the Ultraviolet and Visible: 1. A 'Single-Scattering-Separate' Delta-Eddington Model," Journal of Geophysical Research, Vol. 103, No. D10, 1998, pp.11465-11472. doi:10.1029/98JD00772

[12] D. Lubin, E. H. Jensen and H. P. Gies, "Global Surface Ultraviolet Radiation Climatology from TOMS and ERBE Data," Journal of Geophysical Research, Vol. 103, No. D20, 1998, pp. 26061-26091. doi:10.1029/98JD02308

[13] T. Koskela, P. Tallas and E. Kyrö, "Measured and Modeled UV-B Spectrum Compared with Some Atmospheric Parameters," In: K. H. Stamnes, Ed., Atmospheric Radiation, Proceeding of SPIE 2049, Tromso, 30 June 1993, pp. 296-306. doi:10.1117/12.163526

[14] J. Zeng, R. McKenzie, K. Stamnes, M. Wineland and J. Rosen, "Measured UV Spectra Compared with Discrete Ordinate Method Simulations," Journal of Geophysical Research, Vol. 99, No. D11, 1994, pp. 23019-23030. doi:10.1029/94JD02145

[15] B. Mayer, G. Seckmeyer and A. Kyling, "Systematic Long-Term Comparison of Spectral UV Measurements and UVSPEC Modeling Results," Journal of Geophysical Research, Vol. 102, No. D7, 1997, pp. 8755-8767. doi:10.1029/97JD00240

[16] E. Leontyeva and K. Stamnes, "Estimations of Cloud Optical Thickness from Ground-Based Measurements of Incoming Solar Radiation in the Arctic," Journal of Climate, Vol. 7, No. 4, 1994, pp. 566-578. doi:10.1175/1520-0442(1994)007<0566:EOCOTF $>2.0 . C$ $\underline{\mathrm{O} ; 2}$

[17] P. M. de F. Forster, "Modelling Ultraviolet Radiation at the Earth's Surface. Part I: The Sensitivity of Ultraviolet Irradiances to Atmospheric Changes," Journal of Applied Meteorological, Vol. 34, No. 11, 1995, pp. 2412-2425. doi:10.1175/1520-0450(1995)034<2412:MURATE $>2.0$. $\underline{\mathrm{CO} ; 2}$

[18] E. Pachart, J. Lenoble and C. Brogniez, "Consistency Tests on UV Spectral Irradiance Measurements Using Modeling and a Broadband Instrument," Journal of Geophysical Research, Vol. 105, No. D4, 2000, pp. 4851-4856. doi:10.1029/1999JD900812

[19] Atmospheric Environment Service (AES), "Canada's National Environmental Indicator Series: Stratospheric ozone depletion,” Environment Canada, Ontario, 1999.

[20] J. B. Kerr and C. T. McElory, "Evidence for Large Upward Trends of Ultraviolet-B Radiation Linked to Ozone Depletion," Science Magazine, Vol. 262, No. 5136, 1993, pp. 1032-1035. doi:10.1126/science.262.5136.1032

[21] A. F. Bais, C. S. Zerefos and C. T. McElory, "Solar UVB Measurements with the Double and Single Monochromator Brewer Ozone Spectrophotometers," Geophysical
Research Letters, Vol. 23, No. 8, 1996, pp. 833-836. doi:10.1029/96GL00842

[22] J. A. Davies, "Correcting for Stray Light in Brewer Spectroradiometers," Environmental Technology, Vol. 17, No. 4, 1996, pp. 421-426. doi:10.1080/09593331708616402

[23] D. L. Wardle and J. B. Kerr, "Scientific Sponsorship Statement for Brewer Spectral Data from Canadian Stations," WUDC documents, 1999.

[24] A. F. Bais, S. Kazadzis, D. Balis, C. S. Zerefos and M. Blumthaler, "Correcting Global Solar Ultraviolet Spectra Recorded by a Brewer Spectroradiometer for its Angular Response Error," Applied Optics, Vol. 37, No. 27. 1998, pp. 6339-6344. doi:10.1364/AO.37.006339

[25] U. Feister, R. Grewe and K. Gericke, "A Method for Correction of Cosine Errors in Measurements of Spectral UV Irradiance," Solar Energy, Vol. 60, No. 6, 1997, pp. 313-332. doi:10.1016/S0038-092X(97)00030-3

[26] J. R. Herman, N. Krotkov, E. Celarier, D. Larko and G. Labow, "Distribution of UV Radiation at the Earth's Surface from TOMS-Measured UV-Backscattered Radiances," Journal of Geophysical Research, Vol. 104, No. D10, 1999, pp. 12059-12076. doi:10.1029/1999JD900062

[27] P. Wang, Z. Li, J. Cihlar, D. I. Wardle and J. Kerr, "Validation of an UV Inversion Algorithm Using Satellite and Surface Measurements," Journal of Geophysical Research, Vol. 105, No. D4, 2000, pp. 5037-5048. doi:10.1029/1999JD900403

[28] F. Cappellani and C. Kochler, "Temperature Effects Correction in a Brewer MKIV Spectrophtometer for Solar UV Measurements," Journal of Geophysical Research, Vol. 105, No. D4, 1999, pp. 4829-4831. doi:10.1029/1999JD900254

[29] N. A. Krotkov, P. K. Bhartia, J. R. Herman, V. Fioletov and J. Kerr, "Satellite Estimation of Spectral Surface UV Irradiance in the Presence of Tropospheric Aerosols: 1. Cloud-Free Case," Journal of Geophysical Research, Vol. 103, No. D8, 1998, pp. 8779-8793. doi:10.1029/98JD00233

[30] J. L. Michalsky, "The Astronomical Almanac's Algorithm for Approximate Solar Position (1950-2050)," Solar Energy, Vol. 40, No. 3, 1988, pp. 227-235. doi:10.1016/0038-092X(88)90045-X

[31] K. Stamnes, S.-C. Tsay, W. J. Wiscombe and K. Jayawerra, "Numerically Stable Algorithm for Discrete Ordinate Method Radiative Transfer in Multiple Scattering and Emitting Layered Media," Applied Optics, Vol. 27, No. 12, 1988, pp. 2503-2509. doi:10.1364/AO.27.002502

[32] J. H. Joseph, W. J. Wiscombe and J. A. Weinman, "The Delta-Eddington Approximation for Radiative Flux Transfer," Journal of the Atmospheric Sciences, Vol. 33, No. 12, 1976, pp. 2452-2459.

[33] R. J. Paur and A. M. Bass, "The Ultraviolet Cross Sections of Ozone: II. Results and Temperature Dependence" Reidel Publishing, Dordrecht, 1985, pp. 606-616.

[34] L. Elterman, "UV, Visible and IR Attenuation for Altitudes to $50 \mathrm{~km}$," Environmental Research Paper, Air Force Cambridge Research Laboratories, Bedford, 1986, pp. 1-59. 
[35] E. P. Shettle and R. W. Fenn, "Models for the Aerosols of the Lower Atmosphere and the Effects of Humidity Variations on Their Optical Properties," AFGL Technical Report 79-0214, Environmental Research Papers, Air Force Geophysics Laboratory, Bedford, 1979.

[36] F. X. Kneizys, E. P. Shettle, L. W. Abreu, J. H. Chetwynd, G. P.Anderson, W. O. Gallery, J. E. A. Selby and S. A. Clough, "Users Guide to LOWTRAN 7," Technical Report, Air Force Geophysics Laboratory, Bedford, 1988.

[37] J. Binyamin, J. Davies and B. McArthur, "UV-B Cloud Optical Properties for Canada," International Journal of Climatology, Vol. 30, No. 8, 2010, pp.1246-1255.

[38] D. E. Bowker, R. E. Davis, D. I. Myrick, K. Stacy and W. T. Jones, "Spectral Reflectance of Natural Targets for Use in Remote Sensing Studies," NASA Reference Publication 1139, NASA Langley Research Center, Hampton, 1985.

[39] J. E. Hay and D. I. Wardle, "An Assessment of the Uncertainty in Measurements of Solar Radiation," Solar Energy, Vol. 29, No. 4, 1982, pp. 271-278. doi:10.1016/0038-092X(82)90242-0

[40] N. A. Hughes, "Global Cloud Climatologies: A Historical Review," Journal of Applied Meteorology, Vol. 23, No. 5, 1994, pp. 724-750. doi:10.1175/1520-0450(1984)023<0724:GCCAHR >2.0. $\underline{\mathrm{CO} ; 2}$

[41] B. G. Gardiner, A. R. Webb, A.F. Bais, M. Blumthaler, I. Dirmhirn, P. Forster, D. Gillotay, K. Henriksen, M. Huber, P. J. Kirsch, P. C. Simon, T. Svenoe, P. Weihs and C. S. Zerfos, "European Intercomparison of Ultraviolet Spectroradiometers," Environmental Technology, Vol. 14, No. 1, 1993, pp. 25-43. doi:10.1080/09593339309385262

[42] A. F. Bais, B. G. Gardiner, H. Slaper, M. Blumthaler, G. Bernhard, R. McKenize, A. R. Wedd, G. Seckmeyer, B.
Kjeldstad, T. Koskela, P. J. Kirsch, J. Gröbner, J. B. Kerr, S. Kazadzis, K. Leszczynski, D. Wardle, W. Josefsson, C. Brogniez, D. Gillotay, H. Reinen, P. Weihs, T. Svenoe, P. Eriksen, F. Kuik and A. Redondas, "SUSPEN Intercomparison of Ultraviolet Spectroradiometers," Journal of Geophysical Research, Vol. 106, No. D12, 2001, pp. 12509-12525. doi:10.1029/2000JD900561

[43] O. Meinander, S. Kazadzis, M. Blumthaler, L. Ylianttila, B. Johnsen, K. Lakkala, T. Koskela, and W. Josefsson, "Diurnal Discrepancies in Spectral Solar UV Radiation Measurements," Applied Optics, Vol. 45, No. 21, 2006 , pp. 5346-5357. doi:10.1364/AO.45.005346

[44] J. A. Davies and D. C. McKay, "Estimating Solar Irradiance and Components," Solar Energy, Vol. 29, No. 1, 1982, pp. 55-64. doi:10.1016/0038-092X(82)90280-8

[45] J. A. Davies and D.C. McKay, "Evaluation of Selected Models for Estimating Solar Radiation on a Horizontal Surfaces," Solar Energy, Vol. 43, No. 3, 1989, pp.153-168. doi:10.1016/0038-092X(89)90027-3

[46] G. Norsang, L. Kocbach, W. Tsoja, J. J. Stamnes, A. Dahlback and P. Nema, "Ground-Based Measurements and Modelling of Solar UV-B Radiation in Lhasa, Tibet," Atmospheric Environment, Vol. 43, No. 9, 2009, pp. 1498-1502. doi:10.1016/i.atmosenv.2008.11.048

[47] B. Chertock, R. Frouin and C. Gautier, "A Technique for Global Monitoring of Net Solar Irradiance at the Ocean Surface. Part II: Validation," Journal of Applied Meteorology, Vol. 31, No. 9, 1992, pp. 1067-1083. doi:10.1175/1520-0450(1992)031<1067:ATFGMO>2.0. $\underline{\mathrm{CO} ; 2}$

[48] T. J. Wang, K. S. Lam, Q. Liu and T. K. Chan, "Assessment of Long Term UV Radiation Measured by the Brewer Spectrophotometer in Hong Kong During 1995-2005," Atmospheric and Climate Sciences, Vol. 1, No. 1, 2011, pp. 9-17. doi:10.4236/acs.2011.11002 